NASA/TM-2005-213858

\title{
Design Study of Wafer Seals for Future Hypersonic Vehicles
}

Patrick H. Dunlap, Jr., Joshua R. Finkbeiner, and Bruce M. Steinetz Glenn Research Center, Cleveland, Ohio

Jeffrey J. DeMange

University of Toledo, Toledo, Ohio 
Since its founding, NASA has been dedicated to the advancement of aeronautics and space science. The NASA Scientific and Technical Information (STI) Program Office plays a key part in helping NASA maintain this important role.

The NASA STI Program Office is operated by Langley Research Center, the Lead Center for NASA's scientific and technical information. The NASA STI Program Office provides access to the NASA STI Database, the largest collection of aeronautical and space science STI in the world. The Program Office is also NASA's institutional mechanism for disseminating the results of its research and development activities. These results are published by NASA in the NASA STI Report Series, which includes the following report types:

- $\quad$ TECHNICAL PUBLICATION. Reports of completed research or a major significant phase of research that present the results of NASA programs and include extensive data or theoretical analysis. Includes compilations of significant scientific and technical data and information deemed to be of continuing reference value. NASA's counterpart of peerreviewed formal professional papers but has less stringent limitations on manuscript length and extent of graphic presentations.

- TECHNICAL MEMORANDUM. Scientific and technical findings that are preliminary or of specialized interest, e.g., quick release reports, working papers, and bibliographies that contain minimal annotation. Does not contain extensive analysis.

- CONTRACTOR REPORT. Scientific and technical findings by NASA-sponsored contractors and grantees.
- CONFERENCE PUBLICATION. Collected papers from scientific and technical conferences, symposia, seminars, or other meetings sponsored or cosponsored by NASA.

- SPECIAL PUBLICATION. Scientific, technical, or historical information from NASA programs, projects, and missions, often concerned with subjects having substantial public interest.

- TECHNICAL TRANSLATION. Englishlanguage translations of foreign scientific and technical material pertinent to NASA's mission.

Specialized services that complement the STI Program Office's diverse offerings include creating custom thesauri, building customized databases, organizing and publishing research results ... even providing videos.

For more information about the NASA STI Program Office, see the following:

- Access the NASA STI Program Home Page at http://www.sti.nasa.gov

- E-mail your question via the Internet to help@sti.nasa.gov

- Fax your question to the NASA Access Help Desk at 301-621-0134

- Telephone the NASA Access Help Desk at 301-621-0390

- Write to:

NASA Access Help Desk

NASA Center for AeroSpace Information 7121 Standard Drive

Hanover, MD 21076 
NASA/TM-2005-213858

Design Study of Wafer Seals for Future Hypersonic Vehicles

Patrick H. Dunlap, Jr., Joshua R. Finkbeiner, and Bruce M. Steinetz Glenn Research Center, Cleveland, Ohio

Jeffrey J. DeMange

University of Toledo, Toledo, Ohio

Prepared for the

41st Joint Propulsion Conference and Exhibit cosponsored by the AIAA, ASME, SAE, and ASEE

Tucson, Arizona, July 10-13, 2005

National Aeronautics and

Space Administration

Glenn Research Center 


\section{Acknowledgments}

The authors gratefully acknowledge Dick Tashjian, QSS Group, Inc., for his assistance in test support.

Trade names or manufacturers' names are used in this report for identification only. This usage does not constitute an official endorsement, either expressed or implied, by the National Aeronautics and Space Administration.

Available from

NASA Center for Aerospace Information 7121 Standard Drive

Hanover, MD 21076
National Technical Information Service 5285 Port Royal Road Springfield, VA 22100 


\title{
Design Study of Wafer Seals for Future Hypersonic Vehicles
}

\author{
Patrick H. Dunlap, Jr., Joshua R. Finkbeiner, and Bruce M. Steinetz \\ National Aeronautics and Space Administration \\ Glenn Research Center \\ Cleveland, Ohio 44135 \\ Jeffrey J. DeMange \\ University of Toledo \\ Toledo, Ohio 43606
}

\begin{abstract}
Future hypersonic vehicles require high temperature, dynamic seals in advanced hypersonic engines and on the vehicle airframe to seal the perimeters of movable panels, flaps, and doors. Current seals do not meet the demanding requirements of these applications, so NASA Glenn Research Center is developing improved designs to overcome these shortfalls. An advanced ceramic wafer seal design has shown promise in meeting these needs. Results from a design of experiments study performed on this seal revealed that several installation variables played a role in determining the amount of leakage past the seals. Lower leakage rates were achieved by using a tighter groove width around the seals, a higher seal preload, a tighter wafer height tolerance, and a looser groove length. During flow testing, a seal activating pressure acting behind the wafers combined with simulated vibrations to seat the seals more effectively against the sealing surface and produce lower leakage rates. A seal geometry study revealed comparable leakage for full-scale wafers with 0.125 and 0.25 in. thicknesses. For applications in which lower part counts are desired, fewer 0.25 -in.-thick wafers may be able to be used in place of 0.125 -in.-thick wafers while achieving similar performance. Tests performed on wafers with a rounded edge ( 0.5 in. radius) in contact with the sealing surface resulted in flow rates twice as high as those for wafers with a flat edge. Half-size wafers had leakage rates approximately three times higher than those for full-size wafers.
\end{abstract}

\section{Introduction}

High temperature, dynamic structural seals are required on future hypersonic vehicles in multiple locations. Vehicle airframe seals are required around the edges and hinge lines of movable control surfaces, around landing gear doors, and around access panels and doors (fig. 1). The perimeters of movable hypersonic engine ramps must also be sealed for safe, efficient operation. This includes panel edge seals to seal gaps between the panels and adjacent engine sidewalls as well as seals along hinge lines. Figure 2 illustrates a panel edge seal location in a candidate hypersonic engine for the National Aerospace Plane (NASP). Researchers at NASA Glenn Research Center (GRC) carried out an in-house program to develop seals for the NASP engine and oversaw industry efforts for airframe and propulsion system seal development for this vehicle during the late 1980's and early 1990's (ref. 1). These seals met many requirements but fell short of leakage, durability, and resiliency goals and were not fully developed when the program was terminated. Further seal development occurred at GRC as part of NASA's Next Generation Launch Technology (NGLT) program, but that program was also terminated before the seals could be fully matured. To overcome performance shortfalls, GRC is continuing to develop advanced seals for future hypersonic vehicles as part of several new programs. 


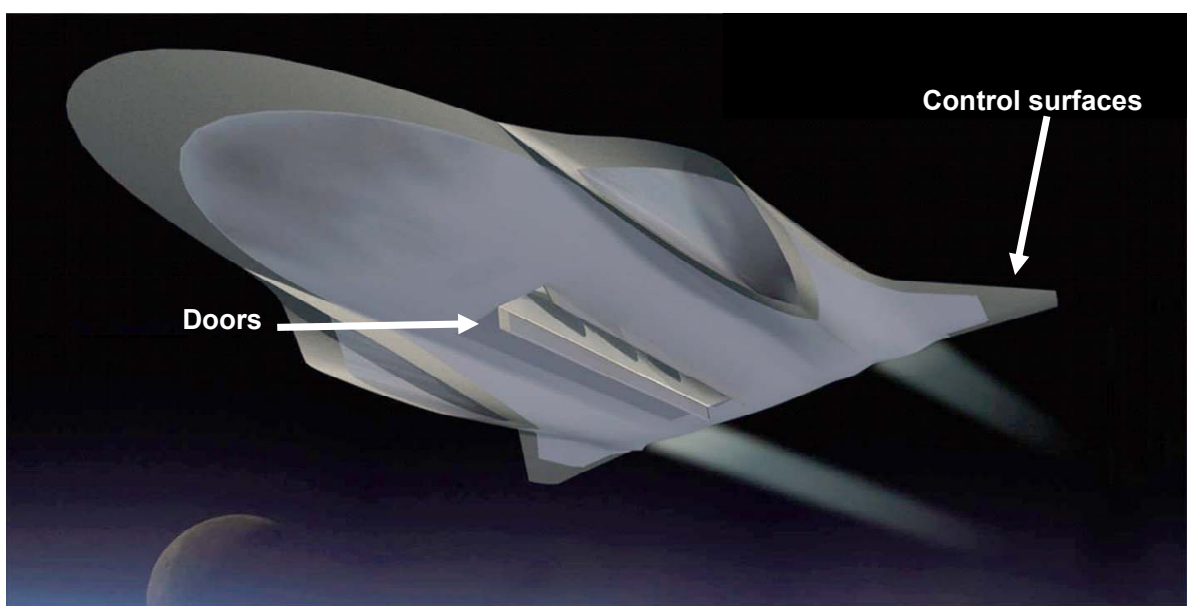

Figure 1.-Airframe seal locations on a future hypersonic vehicle.

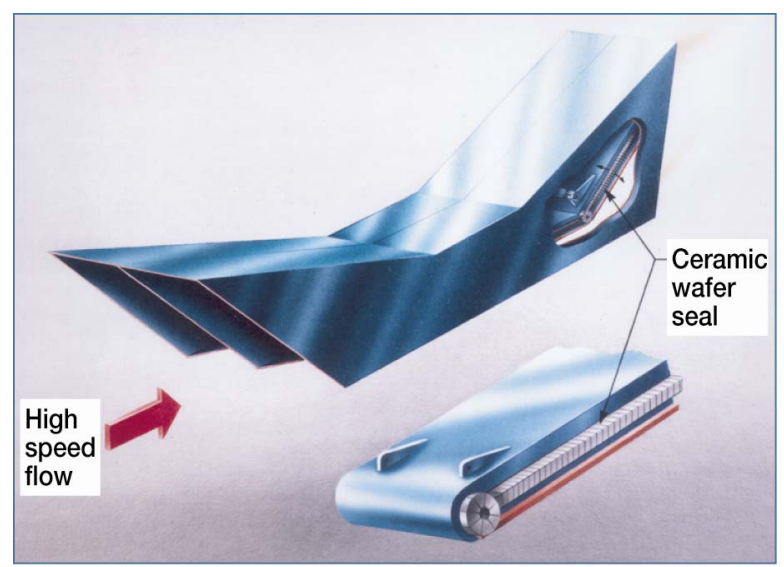

Figure 2.- NASP engine panel edge seals designed to seal the gaps between movable ramps and adjacent engine sidewalls.

\section{A. Seal Design Requirements}

Seals on future hypersonic vehicles must operate in high heat flux, oxidizing environments and restrict the flow of hot gases at extreme temperatures of 2000 to $3000^{\circ} \mathrm{F}$. They must be flexible enough to accommodate distorted sealing surfaces while still providing positive, resilient sealing. In some locations, they must limit loads against sealing surfaces that may be brittle or covered with protective coatings. The seals must also be sufficiently durable to meet required life goals. They must resist scrubbing damage as they are rubbed over rough, distorted sealing surfaces without incurring excessive increases in leakage due to wear. In some locations the seals must seal against rough ceramic matrix composite structures without sticking to coatings on the panel surfaces. The seals must perform all of these functions while still serving as effective flow blockers. Additional details on design requirements for hypersonic engine seals and control surface seals can be found in the papers by Dunlap, et al. (ref. 2) and DeMange, et al. (ref. 3) respectively.

\section{B. Seal Development Approach}

Because of the extreme temperatures involved in these applications, GRC is developing new seal designs that exploit recent advancements in high temperature ceramics. One such design is the ceramic wafer seal shown in figure 3. This seal is composed of a series of thin ceramic wafers installed in a channel on a movable panel and preloaded from behind to maintain contact with the opposing sealing surface. The wafers are able to seal against distorted sealing surfaces by sliding past each other to conform to the shape of the surface. Candidate preload devices include high temperature canted coil springs and compression springs. The study performed by Dunlap, et al. (ref. 2) showed that a system composed of monolithic silicon nitride wafers (Honeywell AS800) is an excellent 

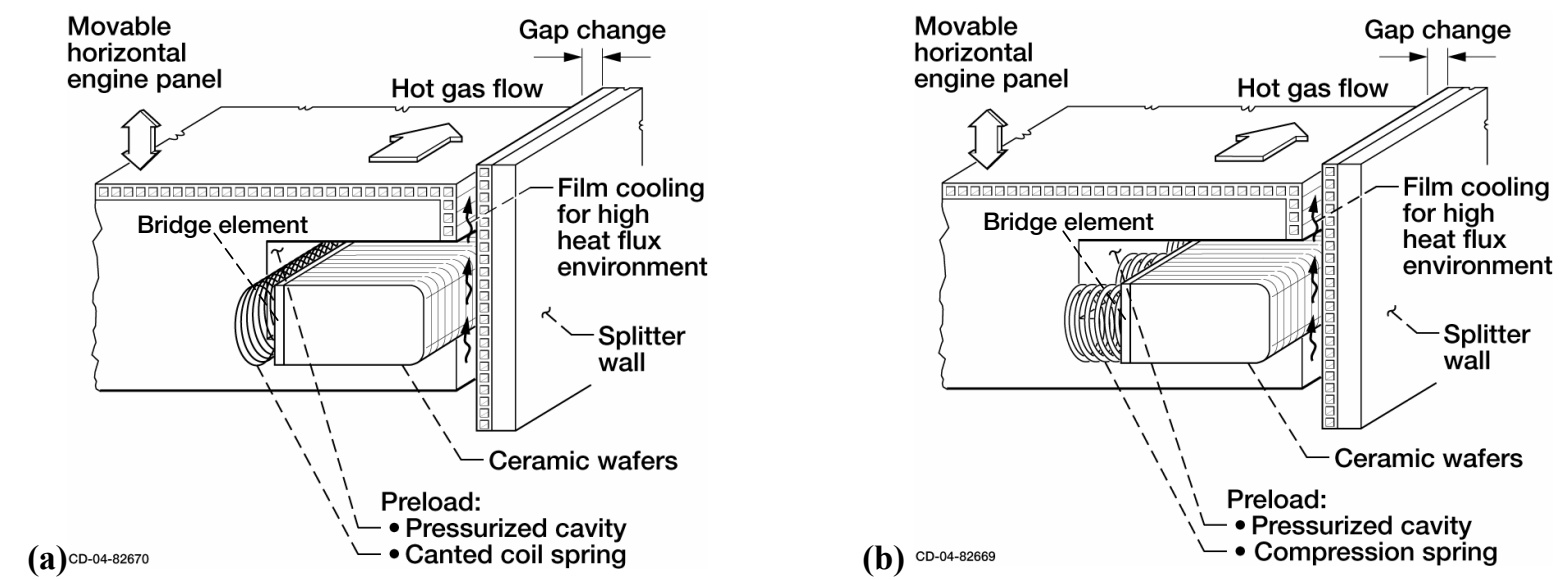

Figure 3.-Schematics of ceramic wafer seal with (a) canted coil springs or

(b) compression springs as preload devices.

candidate to meet the sealing needs of future hypersonic vehicles. Flow rates reported for these wafers were up to 32 times lower than those recorded for the best braided rope seal flow blockers even after 1000 scrub cycles at $2000{ }^{\circ} \mathrm{F}$.

The current study seeks to improve understanding of the ceramic wafer sealing system through parametric studies of its performance. Variables that affect seal installation are addressed, and different wafer seal geometries are evaluated through a series of room temperature flow tests.

\section{Test Apparatus and Procedures}

\section{A. Seal Specimens}

The baseline silicon nitride wafer seal design evaluated in the previous study by Dunlap, et al. (ref. 2) was nominally 0.5 in. wide, 0.92 -in. tall, and 0.125-in. thick with 0.050-in. corner radii (fig. 4). Because the current study focused on flow tests performed at room temperature, and the amount of flow past the wafers was believed to be more a function of wafer geometry than wafer material, it was decided to fabricate seal specimens for this study out of aluminum 7075-T73511. The high temperature capabilities provided by silicon nitride were not required in these room temperature tests. Another factor that guided the wafer

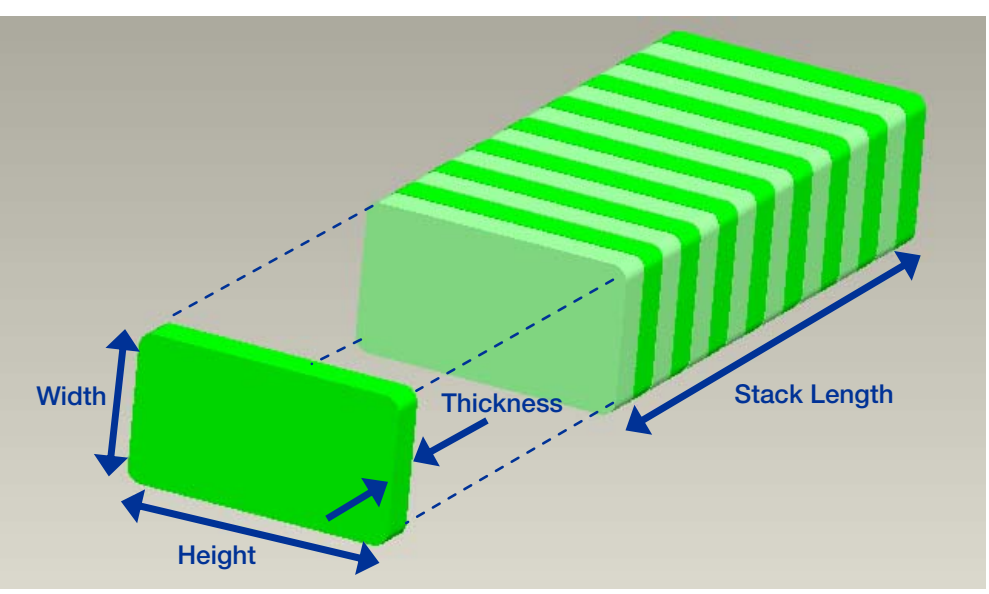

Figure 4.-Wafer seal geometry terminology. material selection for the current study was the extra expense and time involved in making the wafers out of silicon nitride. Fabricating the wafers out of aluminum allowed multiple designs and geometries to be produced more quickly and at a lower cost than if they were made of silicon nitride. The specific wafer geometries evaluated in this study will be described in more detail in the following sections.

\section{B. Flow Test Apparatus}

Room temperature flow tests were performed in a linear flow fixture shown schematically in figure 5 . The flow fixture was designed so that different size seals could be tested in removable cartridges that are inserted into the main body of the test fixture. Seals can be tested in this fixture with different seal gaps and under different amounts of linear compression.

Seals were tested in a groove in the seal cartridge shown in figure 5 . Tests were typically performed using four silicon nitride springs (NHK lot number 4Z20Z11) mounted on 1.15-in. centers to preload the wafers from behind. A bridge element (fig. 3) was used between the springs and wafers to support the wafers and uniformly transfer load. 
For tests performed on smaller wafer seals (e.g., 0.25 in. wide), a stainless steel canted coil spring (BalSeal Part no. 107LBA-LOS-2) was used as the preload device because the silicon nitride springs were too large to fit in the smaller seal groove. Preload was applied to the wafers and springs through an interference fit between the seals and the cover plate. All tests were performed with a 0.125 -in. seal gap. The seal groove length was nominally 4 in., but 0.5 in. on each end of the wafer stack was embedded in the seal cartridge under a "zero-gap" condition. Therefore, an effective seal length of 3 in. was used to calculate flow rates per inch of seal.

Once the cartridge was installed in the flow fixture, an elastomeric O-ring sealed its perimeter to prevent leakage behind the cartridge. A second O-ring sealed between the cover plate and the surface of the test fixture to ensure that the primary leakage path was across the test specimen. Small metal-to-metal contacts existed between the

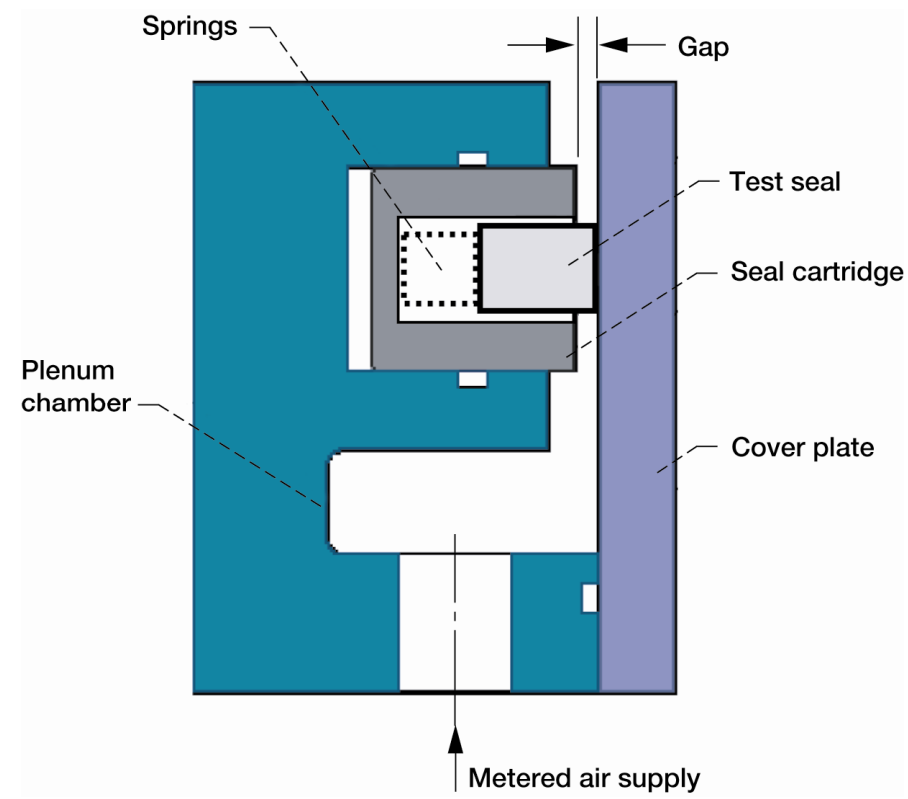

Figure 5.-Cross section schematic of flow fixture. cartridge surface and the cover plate where the O-ring terminated. This junction was sealed with a small amount of RTV which was allowed to cure before testing commenced.

During testing, flow meters upstream of the flow fixture measured the amount of flow that passed through the test seal. The maximum capacity flow meter that was used had a range of 0 to 26.5 standard cubic feet per minute (SCFM) with an accuracy of 1 percent of full scale. A pressure transducer (0 to $100 \mathrm{psig}$, accuracy 0.11 percent of full scale per manufacturer) upstream of the test seal measured the differential pressure across the seal with respect to ambient conditions, and a thermocouple measured the upstream temperature. Another pressure transducer measured the pressure behind the wafers. This pressure was measured to examine how much preload the air pressure exerted on the seal.

Future hypersonic vehicle seals will likely be subjected to environmental conditions that include a fair amount of vibration. This includes seal locations both in a hypersonic engine and on the vehicle's airframe where the seals will be actuated during use, and vibrations will be transmitted to the seals through the structures around them. For the wafer seal design, these movements and vibrations may help to seat individual wafers and align them better against the sealing surface, especially when acting in concert with a pressure differential across the seals. This could ultimately result in lower leakage past the seals.

To simulate vibrations that the seals may experience during use, each flow test was performed in two stages. During the first part of the test, flow rates past the seals were recorded as the pressure across the seals was gradually increased up to $100 \mathrm{psig}$. When the pressure reached $100 \mathrm{psig}$, the flow test fixture was hit lightly with a rubber mallet three or four times to simulate vibrations in the surrounding structures. The flow fixture was then depressurized, and the flow test was repeated. Flow rates before and after the simulated vibrations were then compared. More detailed descriptions of the hardware and procedure used to perform the flow tests can be found in the paper by Dunlap, et al. (ref. 4).

\section{Design of Experiments Study: Seal Installation}

Previous tests performed on the baseline wafer seal design identified a number of factors that seemed to influence the flow-blocking characteristics of these seals. Many of these factors related to how the seals were installed in the seal cartridge during flow testing. Because of this, a study was conducted to evaluate the significance of these factors and how they may interact with each other to affect the amount of leakage past the wafer seals.

The wafers evaluated in this portion of the study had comparable dimensions to the baseline wafers evaluated in the previous study by Dunlap, et al. (ref. 2). They were nominally 0.5 in. wide, $0.92 \mathrm{in.} \mathrm{tall,} \mathrm{and} 0.125 \mathrm{in}$. thick with 0.050 in. corner radii. The factors evaluated in this study are summarized in Table 1. Each factor was evaluated at two levels, high $(+)$ and low (-). Wafer height tolerance referred to the difference in height (i.e., 0.92 in. dimension) between wafers along the length of the 4-in. stack of wafers. The previous study by Dunlap, et al. (ref. 2) indicated that a tighter wafer height tolerance contributed to lower flow rates past the seals, so this variable was deemed worthy of further investigation. 
TABLE 1.-SEAL INSTALLATION VARIABLES EVALUATED IN DOE STUDY

\begin{tabular}{|l|c|c|}
\hline \multicolumn{1}{|c|}{ Factor } & \multicolumn{2}{|c|}{ Levels } \\
\hline & High (+) & Low (-) \\
\hline Wafer height tolerance (in.) & 0.0020 & 0.0003 \\
\hline Groove width clearance (in.) & 0.007 & 0.001 \\
\hline Groove length clearance (in.) & 0.005 & 0.001 \\
\hline Preload (lbf per inch of seal) & 4.3 & 1.8 \\
\hline Bridge element thickness (in.) & 0.060 & 0.015 \\
\hline
\end{tabular}

The dimensions of the groove in which the wafers were installed also seemed to play a role in determining seal leakage in previous tests. The width of the groove with respect to the seal width (i.e., 0.5-in. dimension) was evaluated as well as the length of the seal groove with respect to the overall length of a stack of wafers. Groove width was varied by using two different seal cartridges. One cartridge had a tighter groove width of $0.501 \mathrm{in}$. (0.001-in. groove width clearance), while the other had a looser fit around the wafers with a width of $0.507 \mathrm{in}$. (0.007-in. groove width clearance). Groove length clearance was varied by modifying the thickness of a single wafer in each stack to set up a loose $(0.005 \mathrm{in}$.) or tight $(0.001 \mathrm{in}$.) clearance with respect to the length of the seal groove.

The final two factors related to how the wafers were preloaded from behind by four silicon nitride compression springs. The amount of preload applied to the wafers was evaluated as well as the thickness of the bridge element that supported the wafers. The same springs were used for each test, and the amount of preload was adjusted by using two different levels of compression on the springs.

To rigorously evaluate these factors, a design of experiments (DOE) approach was used (ref. 5). This approach allowed multiple independent variables, or factors, to be considered simultaneously without evaluating all possible combinations of the factor levels. For example, a full factorial design including five two-level factors at high and low levels would require 32 trials $\left(2^{5}=32\right)$. However, a fractional factorial design of the same five two-level factors can be performed using only 16 trials. Whereas a full factorial design permits evaluation of all the main effects (i.e., most important factors) and factor interactions, fractional factorial designs assess the factors at various resolutions. For the purposes of this study, a resolution $\mathrm{V}$ design was selected in which all main effects and two-factor interactions could be evaluated independently and were not confounded (i.e., mixed up) with other main effects or two-factor interactions. Main effects and two-factor interactions are typically considered the most important contributors in this type of study.

The test matrix shown in Table 2 provides details for all 16 trials that were conducted including levels for the five factors evaluated in each room temperature flow test. The trials are presented in the order that they were generated by the software package MINITAB Release 14 (Minitab, Inc.). The actual sequence in which the trials were performed was randomized to minimize any biases that could occur if they were performed in their original asgenerated order. The order in which the trials were performed is also indicated in Table 2.

TABLE 2.-TEST MATRIX FOR DOE STUDY: TWO-LEVEL RESOLUTION V FACTORIAL DESIGN WITH 16 TRIALS (Note: Cells in which high level settings exist are shaded to help visualize patterns within test matrix)

\begin{tabular}{|c|c|c|c|c|c|c|}
\hline $\begin{array}{c}\text { Trial ID } \\
\text { number }\end{array}$ & $\begin{array}{c}\text { Run } \\
\text { order }\end{array}$ & $\begin{array}{c}\text { Wafer height } \\
\text { tolerance } \\
\text { (in.) }\end{array}$ & $\begin{array}{c}\text { Preload } \\
\text { (lbf per inch of seal) }\end{array}$ & $\begin{array}{c}\text { Bridge element } \\
\text { thickness } \\
\text { (in.) }\end{array}$ & $\begin{array}{c}\text { Groove width } \\
\text { clearance } \\
\text { (in.) }\end{array}$ & $\begin{array}{c}\text { Groove length } \\
\text { clearance } \\
\text { (in.) }\end{array}$ \\
\hline 1 & 5 & 0.0003 & 1.8 & 0.015 & 0.001 & 0.005 \\
\hline 2 & 13 & 0.0020 & 1.8 & 0.015 & 0.001 & 0.001 \\
\hline 3 & 11 & 0.0003 & 4.3 & 0.015 & 0.001 & 0.001 \\
\hline 4 & 8 & 0.0020 & 4.3 & 0.015 & 0.001 & 0.005 \\
\hline 5 & 16 & 0.0003 & 1.8 & 0.060 & 0.001 & 0.001 \\
\hline 6 & 12 & 0.0020 & 1.8 & 0.060 & 0.001 & 0.005 \\
\hline 7 & 15 & 0.0003 & 4.3 & 0.060 & 0.001 & 0.005 \\
\hline 8 & 3 & 0.0020 & 4.3 & 0.060 & 0.001 & 0.001 \\
\hline 9 & 10 & 0.0003 & 1.8 & 0.015 & 0.007 & 0.001 \\
\hline 10 & 1 & 0.0020 & 1.8 & 0.015 & 0.007 & 0.005 \\
\hline 11 & 14 & 0.0003 & 4.3 & 0.015 & 0.007 & 0.005 \\
\hline 12 & 9 & 0.0020 & 4.3 & 0.015 & 0.007 & 0.001 \\
\hline 13 & 6 & 0.0003 & 1.8 & 0.060 & 0.007 & 0.005 \\
\hline 14 & 4 & 0.0020 & 1.8 & 0.060 & 0.007 & 0.001 \\
\hline 15 & 2 & 0.0003 & 4.3 & 0.060 & 0.007 & 0.001 \\
\hline 16 & 7 & 0.0020 & 4.3 & 0.060 & 0.007 & \\
\hline
\end{tabular}




\section{Seal Geometry Study}

After the seal installation DOE study was completed, another study was conducted to evaluate the effects of wafer geometry on seal leakage. A series of room temperature flow tests was performed on a variety of different wafer shapes and sizes. Each test was performed using the best combination of the five seal installation factors as determined by the results from the DOE study.

Four different wafer thicknesses were evaluated: 0.125 in. (baseline thickness), 0.25, 1.0, and 2.0 in. (fig. 6(a)) Each wafer was nominally 0.5 in. wide and 0.92 in. tall with 0.050 in. corner radii. With increasing thickness, fewer wafers were required to fill the 4-in. groove. It was theorized that fewer wafers would lead to less gaps between wafers, which could result in lower flow rates. However, fewer wafers would also be less able to conform to distortions of the sealing surface.

In addition to evaluating various wafer thicknesses, a comparison was made between wafers that were flat on each side versus wafers that had a rounded edge in contact with the sealing surface (fig. 6(b)). Wafers with a 0.5-in. radius were used in this study, and both sets of wafers were nominally 0.5 in. wide, 0.92 in. tall, and 0.125 in. thick. It was thought that wafers with a rounded edge may perform better against a rounded sealing surface such as may be encountered along the hinge line of a control surface. However, it was unclear how well such a wafer would block flow as compared to a completely rectangular wafer.

The final geometry comparison was made between "full-size" and "half-size" wafers. As shown in figure 6(c), a full-size wafer was considered to be $0.5 \mathrm{in}$. wide by $0.92 \mathrm{in}$. tall, while a half-size wafer was $0.25 \mathrm{in}$. wide by $0.5 \mathrm{in}$. tall. As with the full-size wafers, the half-size wafers were also evaluated in various thicknesses including 0.125 , 0.25 , and 0.5 in. A separate seal cartridge was used for the half-size wafers with a corresponding 0.25 -in. groove width. A stainless steel canted coil spring preloaded the half-size wafers at approximately $3.8 \mathrm{lbf}$ per inch of seal.

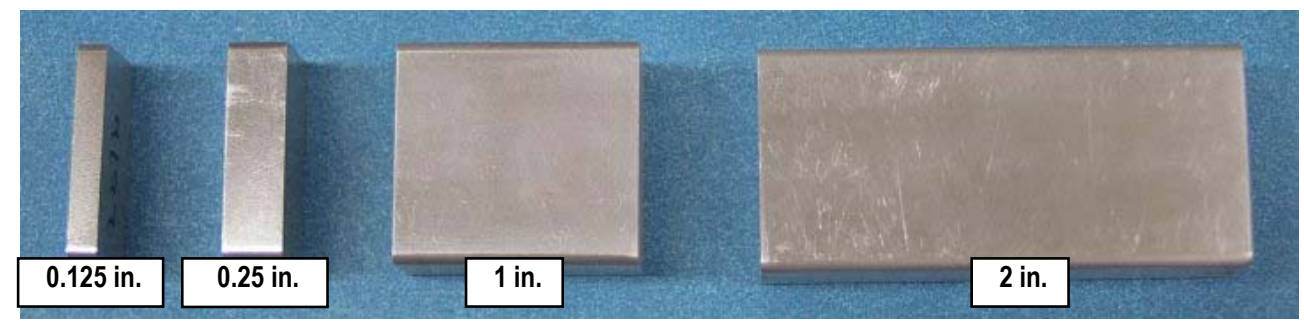

(a)

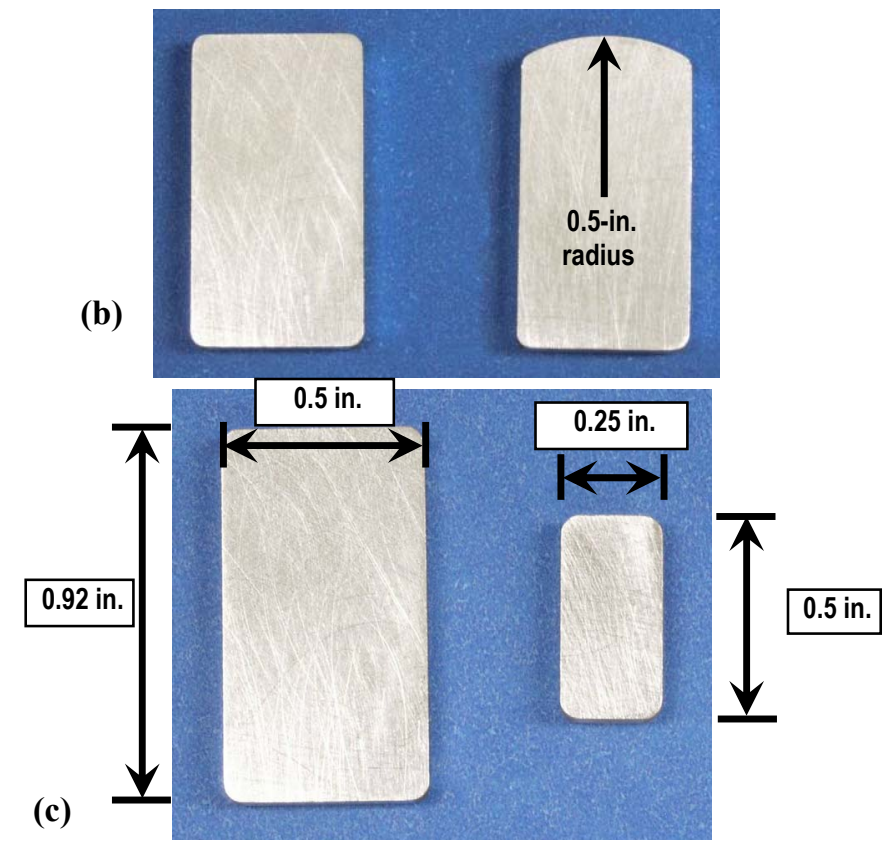

Figure 6.-Wafers evaluated in Seal Geometry Study: (a) wafer thicknesses of 0.125, 0.25, 1.0, and 2.0 in.; (b) flat (left) versus rounded (right) wafers; (c) full-size (left) versus half-size (right) wafers. Note wafer views in (b) and (c) rotated $90^{\circ}$ versus that shown in (a). 


\section{Results and Discussion}

\section{A. Design of Experiments Study: Seal Installation}

\section{Overview of Test Results}

Representative plots of flow data as a function of the pressure differential across the wafers are shown in figures 7 and 8 . These figures are included to show the general shapes of the curves whereas specific comparisons between main effects will be discussed later in the paper. Results are presented both before and after the test fixture was hit with a rubber mallet to simulate vibrations in the system. In both figures, flow rates past the wafers dropped after the simulated vibrations. It is believed that the impulse loads from the mallet jarred the wafers and seated them into a better flow-blocking position against the sealing surface resulting in lower flow rates.

In both figures 7 and 8, flow rates before the simulated vibrations show a steeper slope through the data points recorded from 0 to 5 psig than through the data points at 5 and $20 \mathrm{psig}$. It appears that the rate at which the leakage was increasing lessened once the pressure across the seals reached approximately $5 \mathrm{psig}$. This is thought to be related to a "seal activating" pressure phenomenon that has been observed in previous tests on the wafer seals in which the wafers engaged the sealing surface once a critical pressure was reached (ref. 2). Figure 9 presents pressure data recorded behind the wafers versus the pressure differential across them for the same flow test represented in figure 8. This plot shows a linear relationship between these pressures such that the pressure behind the wafers was equal to about 97 percent of the pressure differential across them. This pressure served as the seal activating pressure that augmented the preload devices to help seat the wafers against the sealing surface. At the start of each trial the wafers were not seated as well against the sealing surface. As the pressure behind the wafers increased, it reached a point where it was able to overcome the friction between adjacent wafers to move them into a better flow-blocking position against the sealing surface. At this point (i.e., between 5 and $20 \mathrm{psig}$ ) the rate at which the leakage was increasing lessened as shown in figures 7 and 8 . When the test fixture was hit with the mallet at a pressure differential of $100 \mathrm{psig}$, the seals were seated even more effectively. It is believed that the seal activating pressure behind the wafers acted in concert with the simulated vibrations to seat the seals and produce lower flow rates as illustrated by the "After simulated vibrations" curve on each plot.

Figures 7 and 8 both show that flow rates dropped after the test fixture was hit with a rubber mallet several times. However, figure 8 shows a smaller decrease in flow rates after the simulated vibrations than what is shown in figure 7. Both the groove length clearance and bridge element thickness were different between these two trials, and it is believed that the difference in groove length clearance played a key role in determining the flow rates of these two trials. In the trial represented in figure 7 the groove length clearance was 0.001 in., whereas the groove length clearance in figure 8 was 0.005 in. It is believed that a tighter clearance forced the individual wafers together more tightly and prevented them from sliding past each other as freely. Because of this, the seal activating pressure may have been less effective in overcoming the friction between wafers and seating them before the simulated vibrations were applied to the system. When the test setup was hit with the mallet while at $100 \mathrm{psi}$, the impulse loads acted with the pressure to seat the seals into a more effective sealing position. Much lower flow rates were then recorded after the simulated vibrations. In contrast, the looser groove clearance $(0.005$ in.) for the trial in figure 8 allowed the wafers to slide past each other more easily and made the seal activating pressure more effective in seating the seals before the hammer hit. This led to lower flow rates throughout the course of the "Before simulated vibrations" portion of the test and less of a difference after the mallet hits. This is further proof that the seal activating pressure and simulated vibrations work together to seat the seals against the sealing surface.

Close examination of figures 7 and 8 reveals a larger increase in flow past the seals when the pressure was increased from 80 to 100 psig than might have been expected based upon the generally linear shape of the curves generated from 0 to $80 \mathrm{psig}$. At the highest pressures (i.e., $100 \mathrm{psig}$ ), post-test observations indicated that leaks may have developed around the ends of the seals, possibly through the RTV in these locations, and that these leaks may have contributed to somewhat higher flow rates at $100 \mathrm{psig}$. For this reason, data points at $100 \mathrm{psig}$ may be suspect and are treated as such in this study. In general, though, these data points do not seem to alter the overall comparisons between trials as they do not dramatically change the shape of the flow versus pressure curves.

It is believed that hitting the test fixture with a rubber mallet while the wafer seals were pressurized at 100 psig was a fair simulation of the vibrations and dynamic movements that could occur during service to seat the seals against the sealing surface. In every trial, the flow past the seals decreased after the mallet hits. For this reason, flow test results presented in future sections are shown after these simulated vibrations. 


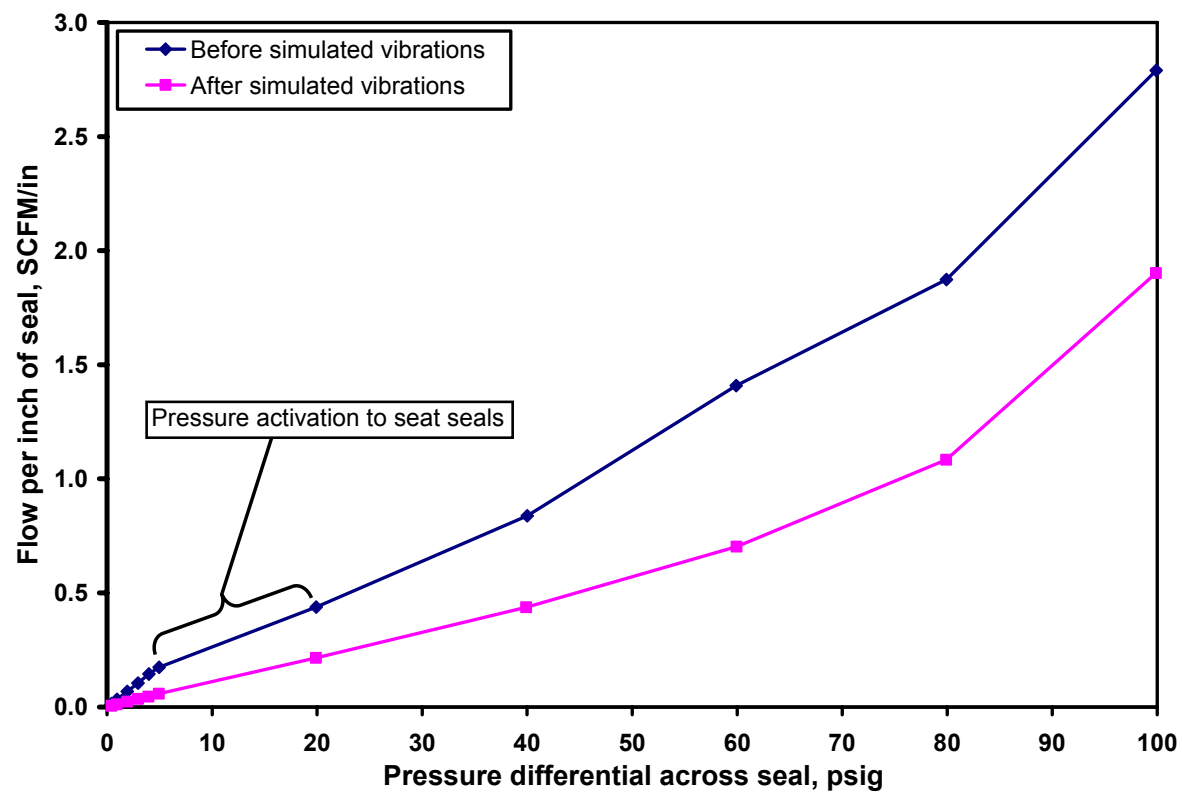

Figure 7.-Flow rates versus pressure differential for Trial ID no. 8 (Run order no. 3) from the DOE study: wafer height tolerance $=0.0020$ in., preload $=4.3 \mathrm{lbf}$ per inch of seal, bridge element thickness $=0.060$ in., groove width clearance $=0.001 \mathrm{in}$., groove length clearance $=0.001 \mathrm{in}$. Results shown before and after test fixture was subjected to simulated vibrations.

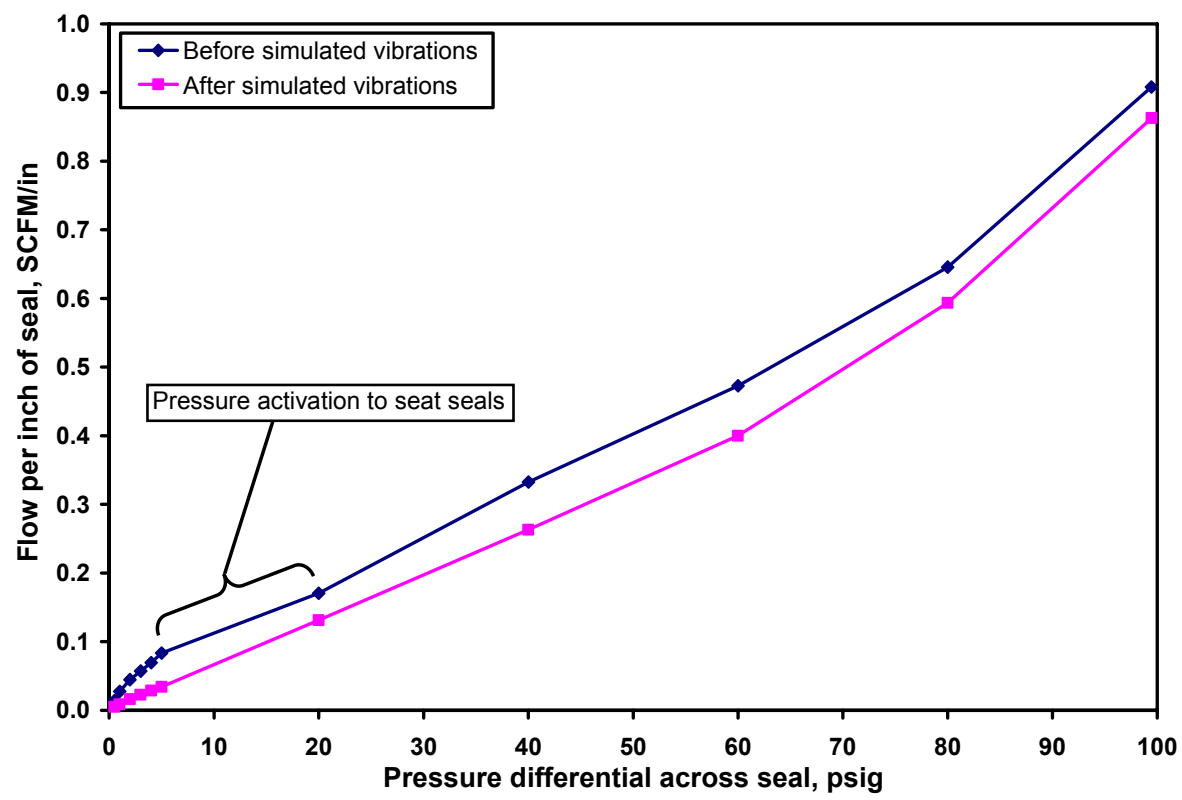

Figure 8.-Flow rates versus pressure differential for Trial ID no. 4 (Run order no. 8) from the DOE study: wafer height tolerance $=0.0020$ in., preload $=4.3 \mathrm{lbf}$ per inch of seal, bridge element thickness $=0.015$ in., groove width clearance $=0.001 \mathrm{in}$, groove length clearance $=0.005$ in. Results shown before and after test fixture was subjected to simulated vibrations. 


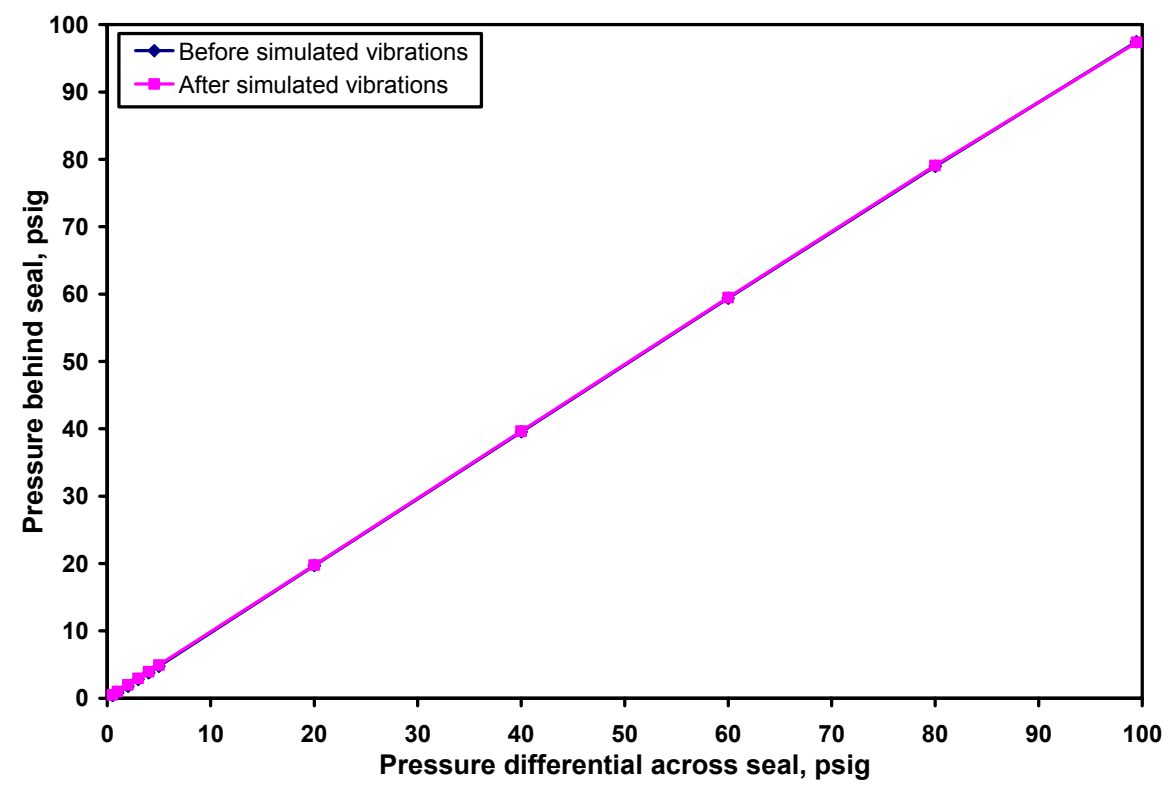

Figure 9.--Pressure behind wafer seals versus pressure differential across seals from

Trial ID no. 4 (Run order no. 8) from the DOE study. Note that pressure behind seal was essentially identical before and after simulated vibrations.

\section{Main Effects}

After all 16 trials were completed for the seal installation DOE study, the results were analyzed using MINITAB. To compare the results of each trial, two different "response values" were used that corresponded to different areas under the flow versus pressure curve. Rather than focusing on seal leakage at a specific pressure value, the area under the curve was selected as a representative leakage metric over a range of pressures. Because the wafer seals are being considered for both hypersonic airframe and propulsion system applications, two different pressure ranges were evaluated. Seal locations on the vehicle airframe typically experience pressure differentials on the order of 5 psig, whereas propulsion system seals would be required to seal pressures up to $100 \mathrm{psig}$. Therefore, the area under the flow versus pressure curve was calculated for each trial over two ranges: 0 to 5 psig and 0 to 100 psig. These results were then input into MINITAB, and the influence of each of the five seal installation variables was evaluated.

Figure 10 shows the main effects plots for a pressure range of 0 to 5 psig, while figure 11 shows a similar set of plots for a pressure range of 0 to $100 \mathrm{psig}$. Both figures present data recorded after the test fixture was hit with the rubber mallet to simulate vehicle vibrations. To interpret these plots, the significance of a given factor is related to the slope of the line such that a steeper slope between the two levels of a factor indicates a stronger influence of that factor on seal leakage. The contrary is also true such that a flatter line indicates less of an influence by a factor.

Figures 10 and 11 show similar trends for each of the five factors. The factor that had the greatest influence (i.e., steepest slope) on seal leakage performance was groove width clearance with a tighter groove producing lower seal leakage rates (figs. 10(d) and 11(d)). It is believed that a tighter groove aligned the wafers better to create a more effective seal between the flat surface of the cover plate and the flat surfaces of the wafers. A looser groove may have allowed the wafers to rock slightly in the groove and seal less effectively against the sealing surface.

The second most influential factor was the amount of preload on the seals. For both pressure ranges, the area under the leakage versus pressure curve dropped when the preload was increased from 1.8 to $4.3 \mathrm{lbf}$ per inch of seal (figs. 10(b) and 11(b)). It is thought that the preload devices played a key role in keeping the wafers in contact with the sealing surface at lower pressures. For example, a preload of $1.8 \mathrm{lbf}$ per inch of seal distributed over the 0.5 -in. seal width generated a sealing contact pressure of $3.6 \mathrm{psi}$, while a preload of $4.3 \mathrm{lbf}$ per inch of seal generated a contact pressure of 8.6 psi. However, as the air pressure behind the wafers increased (fig. 9), it surpassed the preload provided by the springs and became the key source of seal preload at higher pressures. Although this behavior would seem to indicate a stronger influence of seal preload over the lower pressure range, the opposite occurred in this study such that the effect was stronger over the full 100 psig pressure range. This is indicated by the steeper slope in figure 11(b) as compared to that in figure 10(b). Other influential factors such as groove width clearance may have interacted with the seal preload to influence these results. Overall, though, increasing the amount of spring preload behind the wafers produced lower seal leakage rates for both pressure ranges. 


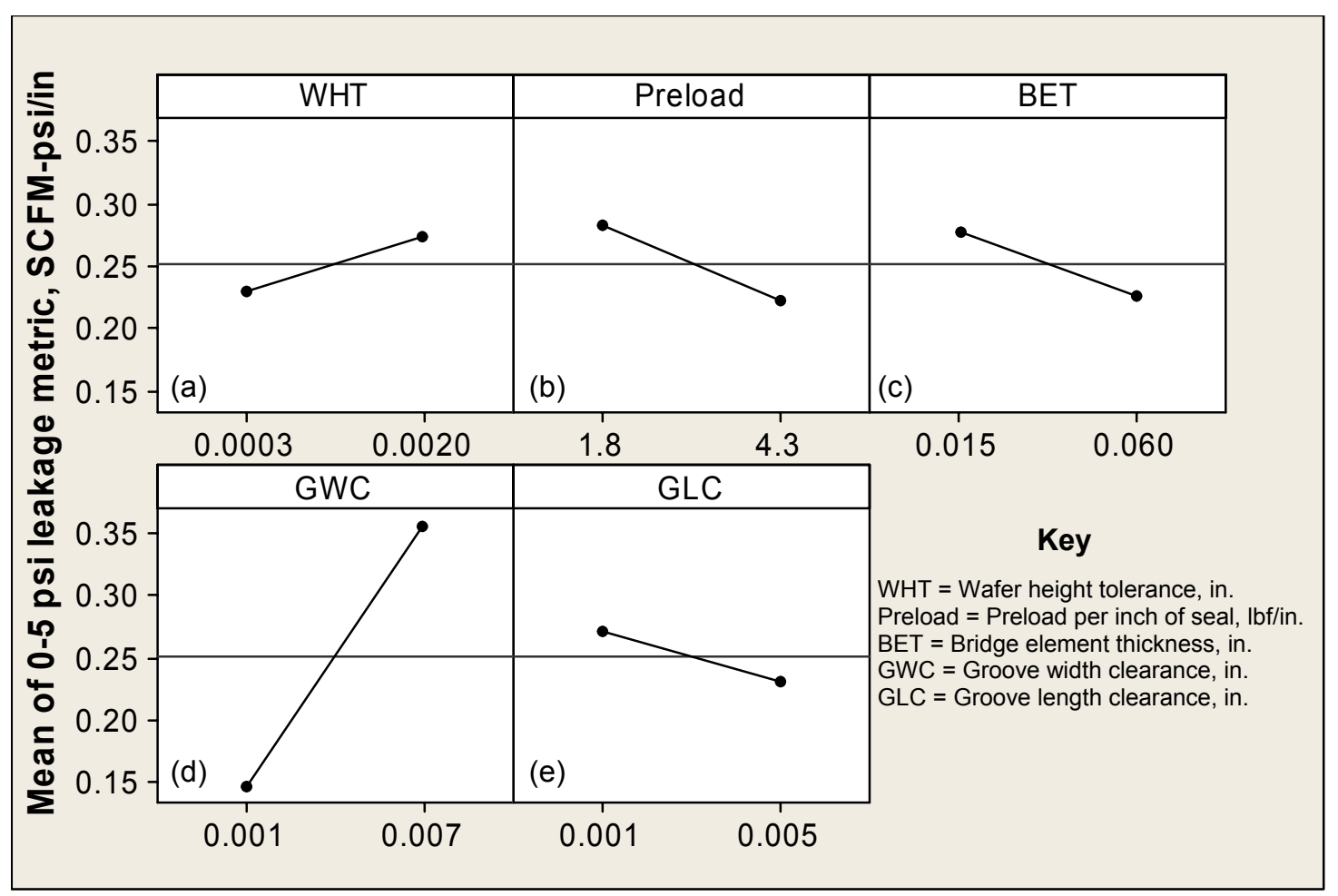

Figure 10.- Main effects plots for seal installation DOE study based on area under flow versus pressure curve from 0 to 5 psig. Results shown after simulated vibrations.

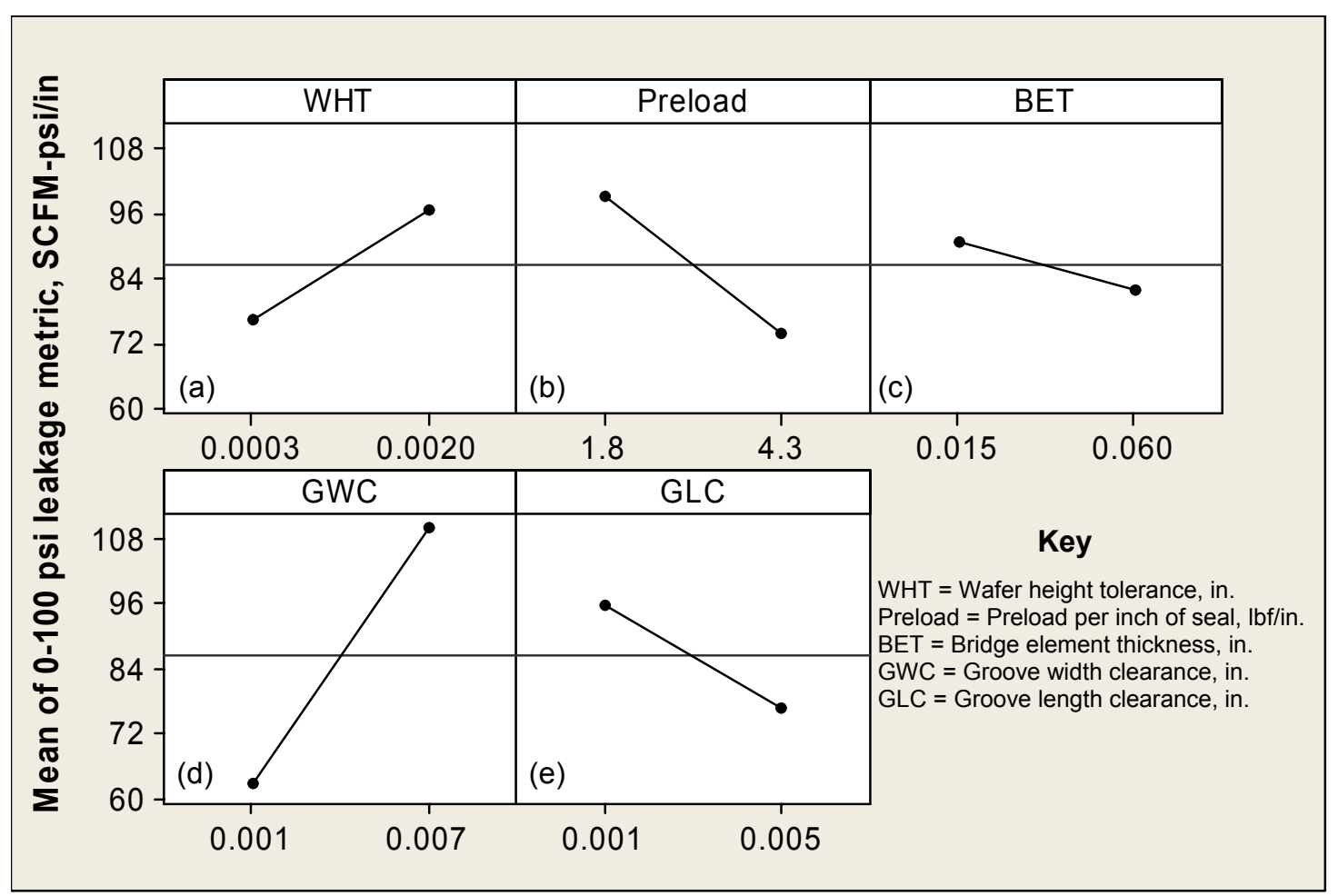

Figure 11.- Main effects plots for seal installation DOE study based on area under flow versus pressure curve from 0 to $100 \mathrm{psig}$. Results shown after simulated vibrations. 
The remaining three factors had less of an influence on seal leakage although all three displayed similar trends in figures 10 and 11. Wafer height tolerance showed a stronger influence over the higher pressure range (fig. 11(a)) than over the lower range (fig. 10(a)) as indicated by the steeper slope in figure 11(a). However, both cases indicated that a tighter tolerance produced lower leakage rates. In a given stack of wafers, some wafers will inevitably be shorter than others. If a tighter tolerance on wafer height is used, the difference in height between individual wafers is minimized. Because the wafers were supported by a solid bridge element in this study, shorter wafers could tend to sit flat against the bridge element and form gaps between the top of the wafer and the sealing surface that could serve as leak paths. A stack of wafers with a tighter height tolerance would presumably have leak paths that are smaller in area as compared to a stack with a larger tolerance. This would then produce lower leakage rates for the stack with the tighter height tolerance, as was evidenced in this case.

Groove length clearance displayed a similar trend as wafer height tolerance in that it had a stronger influence at the higher pressure range (figs. 10(e) and 11(e)). However, in this case a looser groove length clearance led to better seal leakage performance. As discussed previously, it is believed that a tighter clearance forced the individual wafers together more tightly and prevented them from sliding past each other as freely. This may have produced localized areas where groups of wafers did not conform as well to non-uniformities along the sealing surface leading to higher leakage rates. A looser groove length clearance, conversely, allowed the wafers to slide past each and seat better against the sealing surface to produce lower leak rates.

Bridge element thickness had a moderate amount of influence on seal leakage for both pressure ranges. Figures 10(c) and 11(c) both show that a thicker bridge element contributed to lower seal leakage rates. Because the bridge element sat on top of four individual springs and spanned the gaps between those springs, it is believed that a thicker bridge element may have distributed the preload provided by the springs more evenly across the full stack of wafers, thereby keeping them in closer contact with the sealing surface. It is possible that the thinner bridge element may have flexed in the areas between springs and allowed the wafers to move slightly away from the sealing surface in these areas to create small leak paths past the wafers. This would explain the lower leakage rates observed when the thicker bridge element was used. In future applications, a thinner bridge element may be used if a canted coil spring is employed as the preload device behind the wafers (fig. 3(a)). The canted coil spring would load the wafers more uniformly and prevent the flexing that may have occurred between individual compression springs in this study.

\section{Two-Factor Interactions}

In addition to evaluating the main effects from the seal installation DOE study, the two-factor interactions were also assessed. This was done to see if two factors could work together to have an influence on seal leakage that may not have presented itself through consideration of the main effects on their own. As with the main effects evaluation, the response values used for this comparison were the areas under the leakage versus pressure curve for each trial from 0 to 5 psig and from 0 to 100 psig.

Figure 12 shows the interaction plots for a pressure range of 0 to $5 \mathrm{psig}$, while figure 13 shows the plots for a pressure range of 0 to $100 \mathrm{psig}$. Both figures present data recorded after the test fixture was subjected to simulated vehicle vibrations. The level of interaction between two factors is determined by the degree to which the two lines on a plot are out of parallel. Parallel lines indicate little interaction between factors while lines with different slopes indicate a stronger interaction.

The interaction between wafer height tolerance and preload was relatively strong with the biggest difference occurring at the lower preload of $1.8 \mathrm{lbf}$ per inch of seal (figs. 12(a) and 13(a)). At the lower seal preload, it is believed that the springs were less able to seat wafer stacks with a larger height tolerance as shorter wafers in the stack could not be pushed into contact with the sealing surface as effectively. This led to higher flow rates than what was seen for the tighter height tolerance where the low preload was able to keep more of the wafers in contact with the sealing surface. At the higher seal preload of $4.3 \mathrm{lbf}$ per inch of seal, there was little difference in seal performance as the springs were able to effectively load the wafers at both height tolerances.

Another relatively strong interaction occurred between bridge element thickness and groove length clearance (figs. 12(i) and 13(i)). For both pressure ranges, there was little difference in seal performance for a tight length clearance $(0.001 \mathrm{in}$.) regardless of bridge element thickness. However, seal leakage dropped when a thick bridge element was used with the looser groove length clearance. As main effects, these two settings also produced lower leakage rates, so it follows that their combination also generated the best results.

The interaction between wafer height tolerance and groove length clearance was moderately strong (figs. 12(d) and 13(d)). As discussed previously, the tighter groove length clearance of $0.001 \mathrm{in}$. forced individual wafers together more tightly and prevented them from sliding past each other as freely. For a stack of wafers with a larger height tolerance $(0.0020 \mathrm{in}$.), the tighter groove length prevented shorter wafers in the stack from sliding past each other to fill small gaps between them and the sealing surface. This combination of settings ( $0.001 \mathrm{in}$. groove length clearance, $0.0020 \mathrm{in}$. wafer height tolerance) resulted in higher leakage rates. When a groove with a looser length 


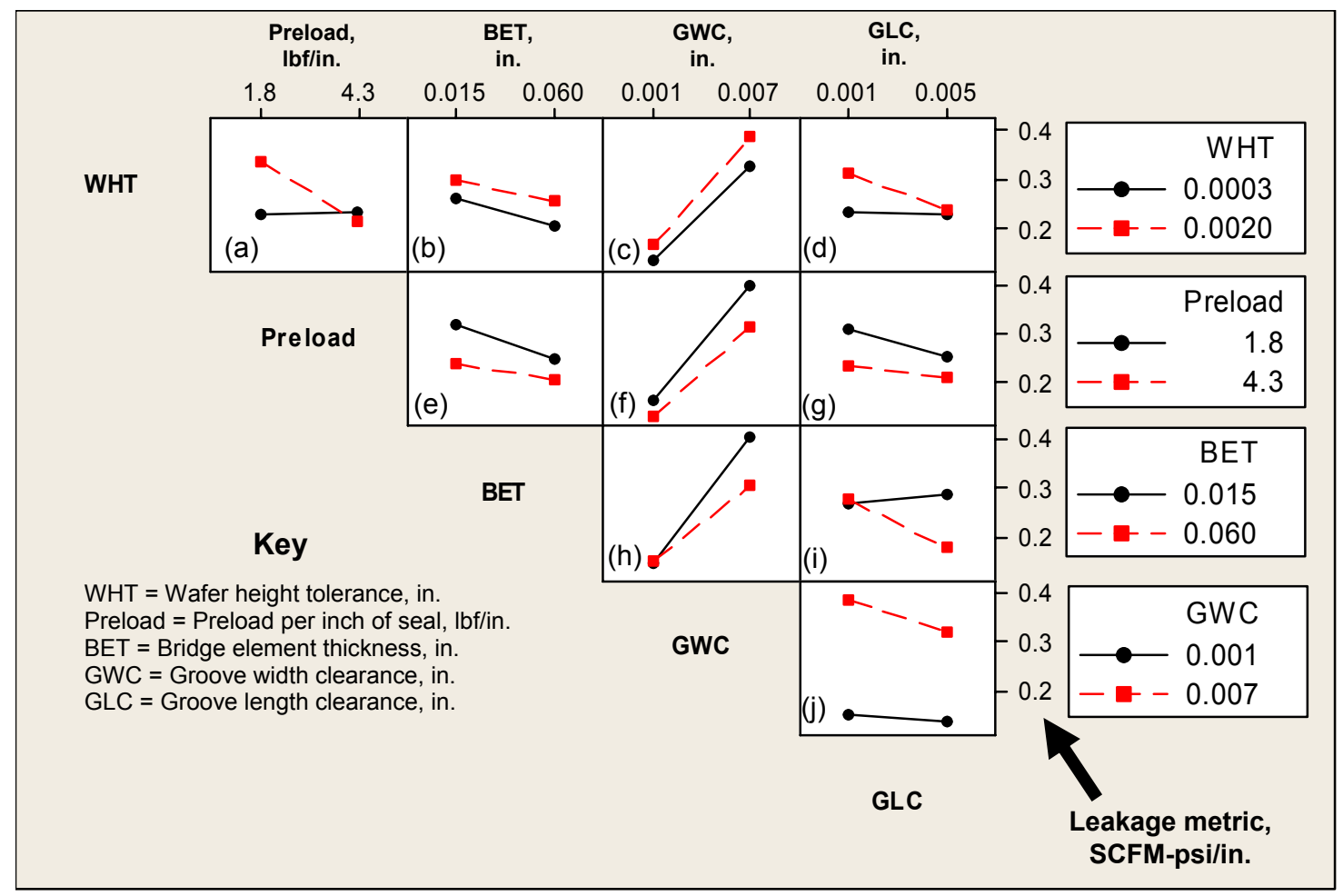

Figure 12.-Two-factor interaction plots for seal installation DOE study based on area under flow versus pressure curve from 0 to 5 psig. Results shown after simulated vibrations.

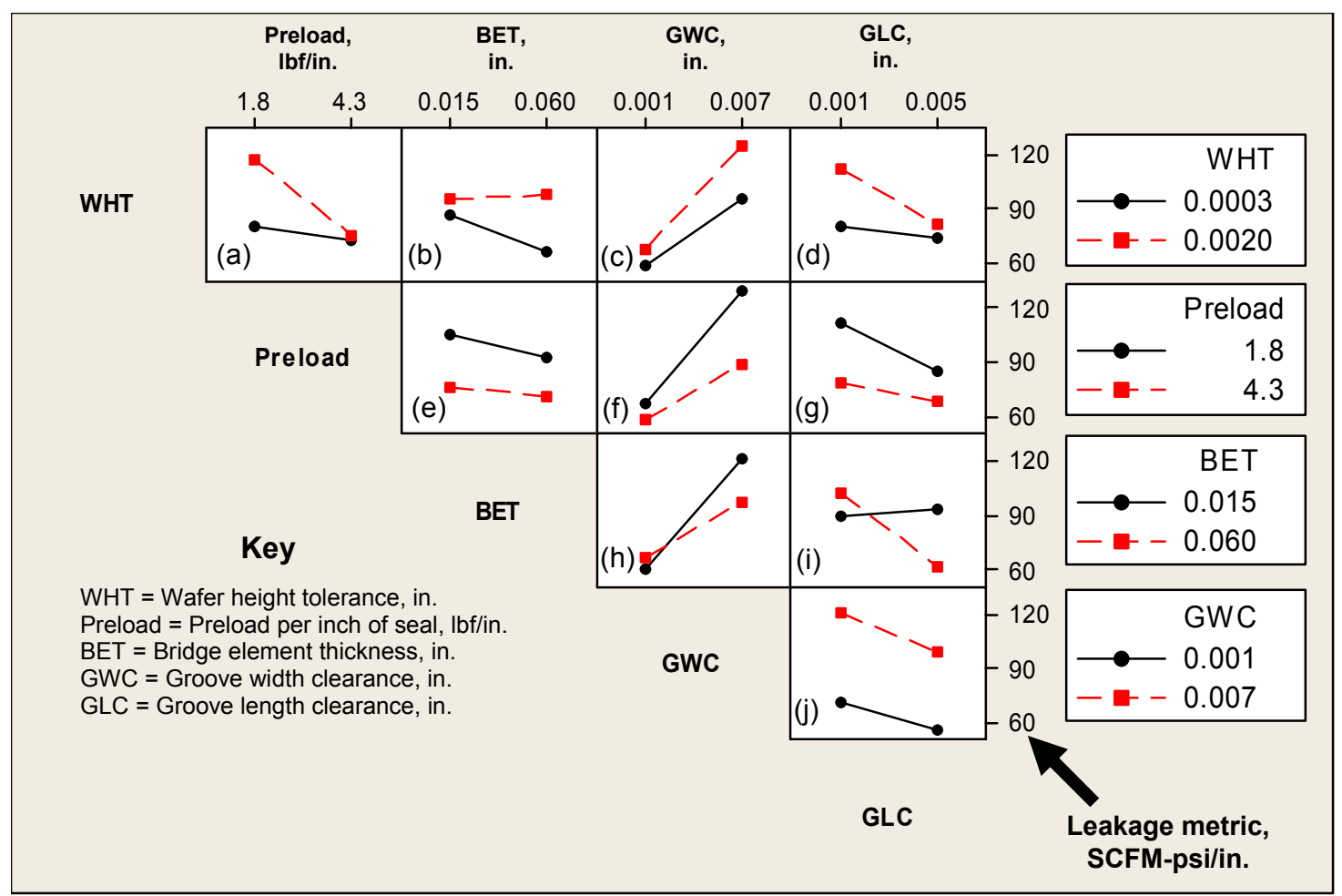

Figure 13.-Two-factor interaction plots for seal installation DOE study based on area under flow versus pressure curve from 0 to $100 \mathrm{psig}$. Results shown after simulated vibrations. 
clearance $(0.005$ in.) was used, the backside air pressure could better seat the wafers, and leakage rates converged for the two levels of wafer height tolerance. Wafers with a tighter height tolerance of $0.0003 \mathrm{in}$. were less sensitive to groove length clearance, as indicated by the nearly flat lines in figures 12(d) and 13(d) for this combination of settings. Because these wafers already presented a more uniform profile against the sealing surface, they were not affected as strongly by the need to slide past each other and the amount of space available to do so. It can be seen from the interaction of these two factors that lower leakage rates can be achieved by using a tighter wafer height tolerance in combination with a looser groove length clearance.

Other two-factor interactions that were moderately strong included the interactions between: bridge element thickness and groove width clearance (figs. 12(h) and 13(h)), wafer height tolerance and bridge element thickness (at high pressures only, fig. 13(b)), and preload and groove width clearance (at high pressures only, fig. 13(f)). The other two-factor interactions were not very strong as indicated by near-parallel lines in the remaining plots.

\section{B. Seal Geometry Study}

After the seal installation DOE study was completed, the best combination of the five seal installation factors was used for another study on various wafer seal shapes and sizes. Based on the results of the DOE study, the following settings were used for this series of room temperature flow tests: a wafer height tolerance of 0.0003 in., a preload of $4.3 \mathrm{lbf}$ per inch of seal, a bridge element thickness of $0.060 \mathrm{in}$., a groove width clearance of $0.001 \mathrm{in}$., and a groove length clearance of 0.005 in.

\section{Wafer Thickness Variations}

Figure 14 presents flow data as a function of the pressure differential across the wafers for several different wafer thicknesses. Each of these wafers was nominally 0.5 in. wide and 0.92 in. tall. As shown previously in figure 6(a), four different wafer thicknesses were evaluated: $0.125 \mathrm{in}$. (baseline thickness), 0.25, 1.0, and $2.0 \mathrm{in}$. It was thought that leakage rates past the seals could be reduced by using thicker wafers. This would allow fewer wafers to be used over the same length, and thus there would be fewer gaps between wafers through which flow could pass.

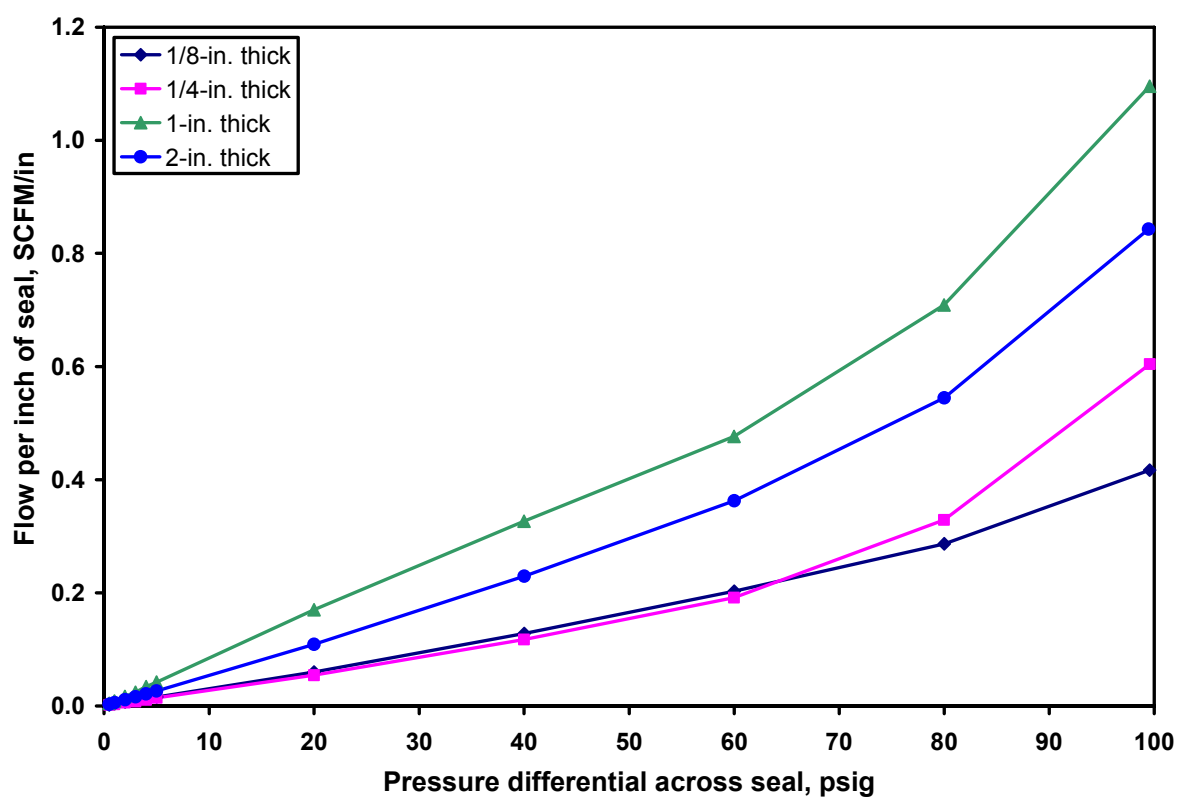

Figure 14.-Flow rates versus pressure differential for wafer thicknesses of 0.125 , $0.25,1.0$, and 2.0 in. Results shown after simulated vibrations. 
Thicker wafers would also lead to lower part counts for an application. However, fewer, thick wafers would be less able to conform to distortions of the sealing surface as compared to an assembly composed of more thin wafers. Figure 14 shows that flow rates for the 0.125 -in.-thick and 0.25 -in.-thick wafers were comparable up to 80 psig with a divergence at $100 \mathrm{psig}$, possibly due to end leakage for the 0.25 in. stack. In comparison, flow rates for the thicker 1 and 2-in. wafers were higher. Measurements taken while the seals were pressurized at 100 psig indicated that the seal gap size increased by approximately 0.001 to $0.002 \mathrm{in}$. as the cover plate bowed outward at this high pressure. An inability of the thicker wafers to conform to misalignments between wafers and distortions along the groove and sealing surface may have caused these higher flow rates.

These results indicate that the part count for a given application can be lowered by using 0.25 -in.-thick wafers instead of 0.125 -in.-thick wafers, and similarly low flow rates can be achieved. However, further increases in wafer thickness generated higher leakage rates. For future applications, wafer thicknesses can be selected based on the anticipated amount of non-uniformity or waviness that the seals would have to accommodate along the sealing surface.

Even though the thicker wafers produced higher flow rates, these flow rates were much lower than those for the best braided rope seal flow blockers (ref. 4). For example, at a pressure differential of 100 psig the flow rate for a 0.6-in.-diameter braided rope seal with a core of uniaxial ceramic fibers (AC1 design) was $11 \mathrm{SCFM} / \mathrm{in}$. with the seal under 20 percent compression. For the same setup, a 0.565 -in.-diameter seal with a core composed of smaller braided rope seals braided together (BC1 design) had a flow rate of $22 \mathrm{SCFM} / \mathrm{in}$. Both of these flow rates are much higher than those shown in figure 14. Compared to the flow rates at 100 psig for the 1-in.-thick wafers, the flow rate for the $\mathrm{AC} 1$ design was 10 times higher and the rate for the $\mathrm{BC} 1$ design was 20 times higher. If the results for the 0.125 -in.-thick wafers are used as the basis for comparison, the $\mathrm{AC} 1$ flow rate was 26 times higher and the $\mathrm{BC} 1$ rate was 52 times higher. In all cases, the wafer seals were much more effective at blocking flow than the braided rope seals were.

2. Flat versus Rounded Wafers

Flow versus pressure data is presented in figure 15 for wafers that were flat on each side versus wafers that had a rounded edge (0.5-in. radius) in contact with the flat sealing surface (fig. 6(b)). Both sets of wafers were nominally 0.5 in. wide, 0.92 in. tall, and 0.125 in. thick. Figure 15 shows that flow rates for the wafers with the rounded edge were nominally twice as high as those for wafers with a flat edge. This difference is likely due to the larger contact footprint that the flat wafers presented against the flat sealing surface versus the smaller footprint of the rounded wafers. Flow through the contact region between the wafers and the sealing surface is believed to be in the viscous regime and is controlled by the length of the flow path. The larger contact footprint of the flat wafers presented a longer flow path that led to lower flow rates.

It is thought that wafers with a rounded edge may conform better against a rounded sealing surface such as may be encountered along the hinge line of a control surface. Because the rounded wafers exhibited flow rates twice as high as those for the flat wafers, any benefits gained by employing the rounded wafers will have to be weighed against the likely increase in flow rates.

3. Full-Size versus Half-Size Wafers

Figure 16 presents flow test results for three different thicknesses of half-size wafers as compared to those for full-size wafers that were $0.125 \mathrm{in}$. thick. The full-size wafers were $0.5 \mathrm{in}$. wide by $0.92 \mathrm{in}$. tall, while the half-size wafers were 0.25 in. wide by 0.5 in. tall (fig. 6(c)). In comparing results for full-size and half-size wafers of the same thickness (i.e., 0.125 in.), flow rates for the half-size wafers were approximately three times higher than those for the full-size wafers. As with the difference between the flat and rounded wafers, this variation is likely due to a difference in contact area between the two wafer sizes. The 0.5 -in.-wide full-size wafers presented a larger contact footprint and thus a longer flow path than did the 0.25 -in.-wide half-size wafers. This longer flow path resulted in lower flow rates for the larger wafers.

Flow rates for the half-size wafers at thicknesses of $0.125,0.25$, and 0.5 in. are also presented in figure 16 . Flow rates for the 0.125 and 0.25 -in.-thick wafers were comparable and varied by less than 10 percent across the full range of pressures. Similar behavior was observed previously for the full-size wafers. Flow rates for the 0.5 -in.-thick half-size wafers were slightly lower than those for the thinner wafers. Based on these results, the wafer count for an application using half-size wafers can be lowered by a factor of four by using 0.5 -in.-thick wafers instead of 0.125 -in.-thick wafers.

Half-size wafers were evaluated in this study because they would occupy less space and weigh less than the fullsize wafers. They would also be able to fit in tighter locations where the full-size wafers cannot be used. However, because the half-size wafers exhibited higher leakage rates, this must be considered in addition to weight and available space when selecting wafer seal sizes for future applications. 


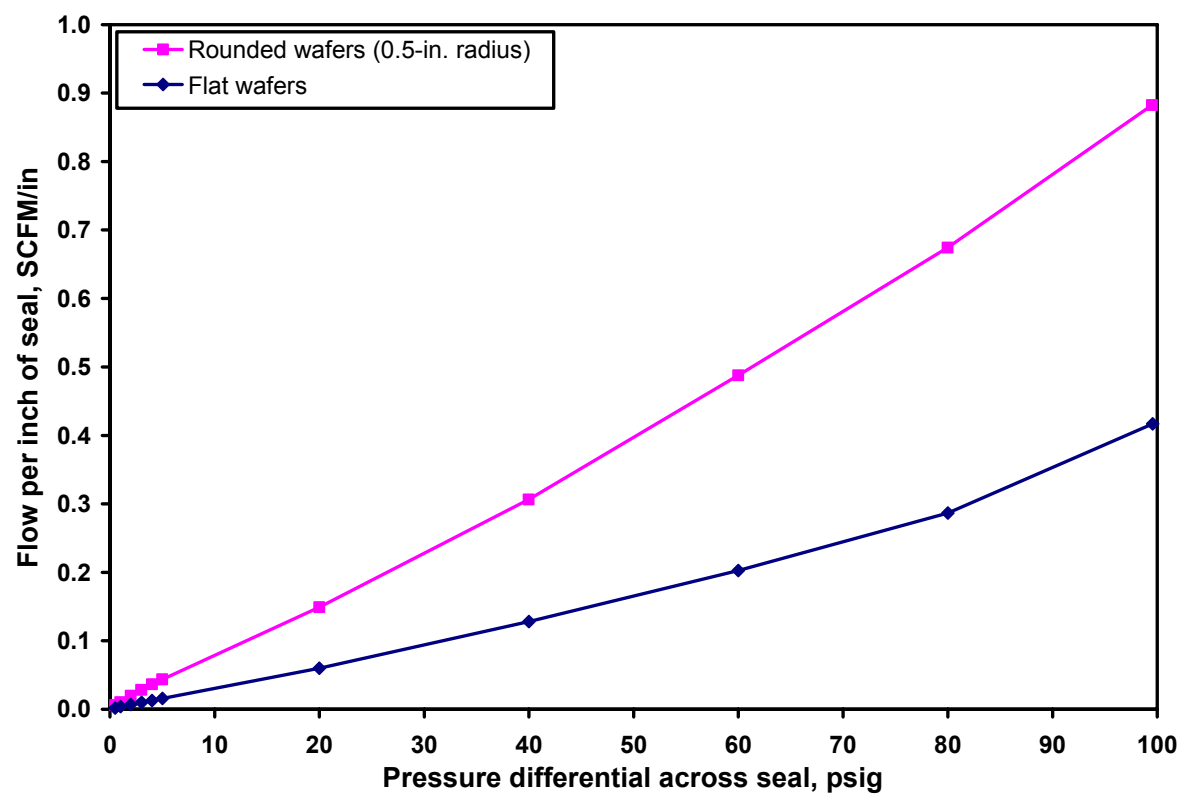

Figure 15.-Flow rates versus pressure differential for flat and rounded wafers. Results shown after simulated vibrations.

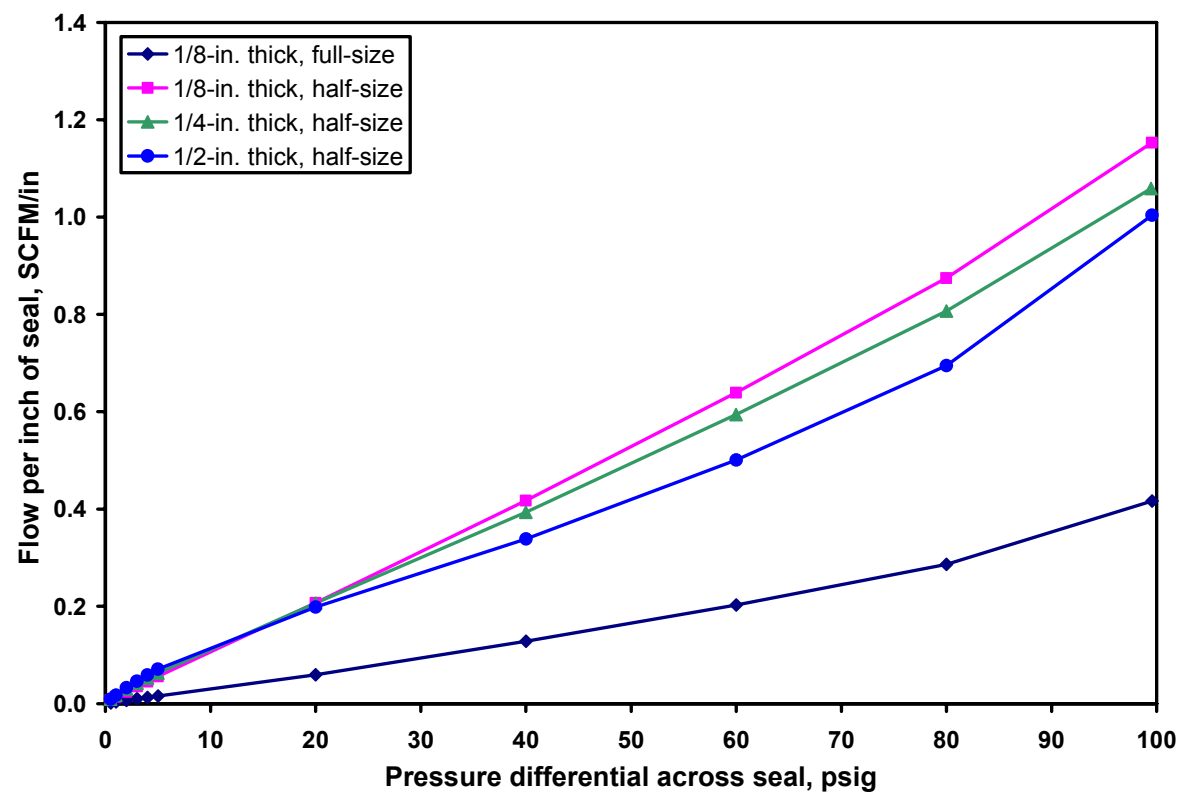

Figure 16.-Flow rates versus pressure differential for full-size and half-size wafers. Results shown after simulated vibrations. 


\section{Summary and Conclusions}

Previous studies on high temperature structural seals revealed that an advanced ceramic wafer seal design is an excellent candidate to meet the sealing needs of future hypersonic vehicles. These studies also identified a number of factors that seemed to influence the flow-blocking characteristics of the seals. Many of these factors were related to how the seals were installed in the seal groove. Because of this, a DOE study was conducted to evaluate the significance of these installation factors and how they may interact with each other to affect the amount of leakage past the wafer seals. After the seal installation DOE study was completed, another study was conducted to evaluate the effects of wafer geometry on seal leakage. Each test was performed using the best combination of the five seal installation factors as determined by the DOE study. Based on the results of these tests, the following conclusions were made:

1. Seal installation factors that contributed to lower leakage rates included a tighter groove width around the seals ( $0.001 \mathrm{in}$. clearance), a higher seal preload ( $4.3 \mathrm{lbf}$ per inch of seal), a tighter height tolerance along the length of a stack of wafers $(0.0003 \mathrm{in}$.), and a looser groove length ( 0.005 in. clearance). A thicker bridge element $(0.060$ in.) between the wafers and the seal preload devices also tended to produce lower leakage rates.

2. The five seal installation factors evaluated in the DOE study often interacted with each other to affect seal leakage rates. The strongest interactions occurred between wafer height tolerance and preload and between bridge element thickness and groove length clearance.

3. During flow testing, a seal activating pressure acted behind the wafers to help seat them more effectively against the sealing surface. A linear relationship was observed such that the pressure behind the wafers was equal to about 97 percent of the pressure differential across them. Seal seating was further enhanced by simulated vibrations applied to the test fixture when the system was pressurized. Lower leakage rates were observed after the seals were seated more effectively against the sealing surface.

4. Comparable leakage rates were recorded for full-size wafers with 0.125 and 0.25 in. thicknesses. However, further increases in wafer thickness ( 1 and 2 in.) generated higher flow rates past the seals. For applications in which lower part counts are desired, fewer 0.25-in.-thick wafers could be used in place of 0.125 -in.-thick wafers with similar performance assuming that the thicker wafers can conform to anticipated waviness in the sealing surface.

5. Flow rates for wafers with a rounded edge ( 0.5 in. radius) in contact with a flat sealing surface were twice as high as those for wafers with a flat edge. For future applications, any benefits gained by employing the rounded wafers will have to be weighed against this likely increase in flow rate.

6. Half-size wafers exhibited leakage rates approximately three times higher than those for full-size wafers. This must be considered in addition to seal weight and available space when selecting wafer seal sizes for future applications.

\section{References}

1. Steinetz, B.M., DellaCorte, C., Machinchick, M., Mutharasan, R., Du, G., Ko, F, Sirocky, P.J., and Miller, J.H., "High Temperature Dynamic Engine Seal Technology Development," NASA TM-105641, April 1992.

2. Dunlap, P.H., Steinetz, B.M., and DeMange, J.J., "Further Investigations of Hypersonic Engine Seals," NASA/TM-2004-213188, August 2004.

3. DeMange, J.J., Dunlap, P.H., and Steinetz, B.M., "Advanced Control Surface Seal Development for Future Space Vehicles," NASA/TM-2004-212898, January 2004.

4. Dunlap, P.H., Steinetz, B.M., DeMange, J.J., and Taylor, S.C., "Toward an Improved Hypersonic Engine Seal," NASA/TM-2003-212531, July 2003.

5. Breyfogle, F.W., Statistical Methods for Testing, Development, and Manufacturing, John Wiley \& Sons, Inc., 1992, Chap. 13. 


\begin{tabular}{|c|c|c|}
\hline \multicolumn{2}{|c|}{ REPORT DOCUMENTATION PAGE } & $\begin{array}{l}\text { Form Approved } \\
\text { OMB No. 0704-0188 }\end{array}$ \\
\hline \multicolumn{3}{|c|}{$\begin{array}{l}\text { Public reporting burden for this collection of information is estimated to average } 1 \text { hour per response, including the time for reviewing instructions, searching existing data sources } \\
\text { gathering and maintaining the data needed, and completing and reviewing the collection of information. Send comments regarding this burden estimate or any other aspect of thi } \\
\text { collection of information, including suggestions for reducing this burden, to Washington Headquarters Services, Directorate for Information Operations and Reports, } 1215 \text { Jefferson } \\
\text { Davis Highway, Suite 1204, Arlington, VA 22202-4302, and to the Office of Management and Budget, Paperwork Reduction Project (0704-0188), Washington, DC 20503. }\end{array}$} \\
\hline 1. AGENCY USE ONLY (Leave blank) & $\begin{array}{l}\text { 2. REPORT DATE } \\
\text { October } 2005\end{array}$ & $\begin{array}{l}\text { D DATES COVERED } \\
\text { echnical Memorandum }\end{array}$ \\
\hline \multicolumn{3}{|c|}{ Design Study of Wafer Seals for Future Hypersonic Vehicles } \\
\hline \multicolumn{3}{|l|}{ 6. AUTHOR(S) } \\
\hline $\begin{array}{l}\text { 9. SPONSORING/MONITORING AGEN } \\
\text { National Aeronautics and Sp } \\
\text { Washington, DC 20546-00 }\end{array}$ & $\begin{array}{l}\text { VAME(S) AND ADDRESS(ES) } \\
\text { Administration }\end{array}$ & $\begin{array}{l}\text { 10. SPONSORING/MONITORING } \\
\text { AGENCY REPORT NUMBER } \\
\\
\text { NASA TM-2005-213858 } \\
\text { AIAA-2005-4153 }\end{array}$ \\
\hline
\end{tabular}

\section{SUPPLEMENTARY NOTES}

Prepared for the 41st Joint Propulsion Conference and Exhibit cosponsored by the AIAA, ASME, SAE, and ASEE, Tucson, Arizona, July 10-13, 2005. Patrick H. Dunlap, Jr., Joshua R. Finkbeiner, and Bruce M. Steinetz, NASA Glenn Research Center; and Jeffrey J. DeMange, University of Toledo, 2801 W. Bancroft Street, Toledo, Ohio 43606.

Responsible person, Patrick H. Dunlap, Jr., organization code RSM, 216-433-3017.

12a. DISTRIBUTION/AVAILABILITY STATEMENT

12b. DISTRIBUTION CODE

Unclassified - Unlimited

Subject Category: 37

Available electronically at http://gltrs.grc.nasa.gov

This publication is available from the NASA Center for AeroSpace Information, 301-621-0390.

13. ABSTRACT (Maximum 200 words)

Future hypersonic vehicles require high temperature, dynamic seals in advanced hypersonic engines and on the vehicle airframe to seal the perimeters of movable panels, flaps, and doors. Current seals do not meet the demanding requirments of these applications, so NASA Glenn Research Center is developing improved designs to overcome these shortfalls. An advanced ceramic wafer seal design has shown promise in meeting these needs. Results from a design of experiments study performed on this seal revealed that several installation variables played a role in determining the amount of leakage past the seals. Lower leakage rates were achieved by using a tighter groove width around the seals, a higher seal preload, a tighter wafer height tolerance, and a looser groove length. During flow testing, a seal activating pressure acting behind the wafers combined with simulated vibrations to seat the seals more effectively against the sealing surface and produce lower leakage rates. A seal geometry study revealed comparable leakage for full-scale wafers with 0.125 and 0.25 in. thicknesses. For applications in which lower part counts are desired, fewer 0.25-in.-thick wafers may be able to be used in place of 0.125-in.-thick wafers while achieving similar performance. Tests performed on wafers with a rounded edge ( 0.5 in. radius) in contact with the sealing surface resulted in flow rates twice as high as those for wafers with a flat edge. Half-size wafers had leakage rates approximately three times higher than those for full-size wafers.

\begin{tabular}{l|l}
\hline 14. SUBJECT TERMS & 15. NUMBER OF PAGES
\end{tabular}

Seals; Flow; Design; Test; High temperature

22

16. PRICE CODE

\begin{tabular}{|c|c|c|}
\hline $\begin{array}{c}\text { 17. SECURITY CLASSIFICATION } \\
\text { OF REPORT } \\
\text { Unclassified }\end{array}$ & $\begin{array}{c}\text { 18. SECURITY CLASSIFICATION } \\
\text { OF THIS PAGE } \\
\text { Unclassified }\end{array}$ & $\begin{array}{c}\text { 19. SECURITY CLASSIFICATION } \\
\text { OF ABSTRACT } \\
\text { Unclassified }\end{array}$ \\
\hline
\end{tabular}

NSN 7540-01-280-5500

Standard Form 298 (Rev. 2-89)

Prescribed by ANSI Std. Z39-18 298-102 

